\title{
Concentration of 'Oblachinska' sour cherry juice using osmotic distillation
}

\author{
Racz, G. ${ }^{1}$, Papp, N. ${ }^{2}$, Hegedüs, A. ${ }^{3}$, Szabó, Z. ${ }^{4}$, Nyéki, J. ${ }^{4}$, Szabó, T. ${ }^{5}$ \\ Stefanovits-Bányai, É. ${ }^{2}$ \& Vatai, Gy. ${ }^{1}$ \\ ${ }^{1}$ Corvinus University of Budapest, Department of Food Engineering, 1118 Budapest, Villányi út 29., Hungary \\ ${ }^{2}$ Corvinus University of Budapest, Department of Applied Chemistry, 1118 Budapest, Villányi út 29., Hungary \\ ${ }^{3}$ Corvinus University of Budapest, Department of Genetics and Plant Breeding, 1118 Budapest, Villányi út 29., \\ Hungary \\ ${ }^{4}$ University of Debrecen, Centre of Agricultural Sciences, H-4032, Debrecen, Hungary \\ ${ }^{5}$ Research and Extension Centre for Fruit Growing, H-4244 Újfehértó, Vadastag 2. \\ E-mail: gabor.racz2@uni-corvinus.hul
}

\begin{abstract}
Summery: Sour cherry is one of the most famous and characteristic Hungarian fruit what is also commonly used in food production as a colour additive. The sour cherry cultivar, 'Oblachinska' was shown to be a rich source of antioxidant compounds, including mainly anthocyanins. Valuable compounds in fruit juice - vitamins, polyphyenols etc. -are heat-sensitive molecules, which should be taken into account during the process of concentration to prevent degradation. Osmotic distillation seems a suitable option to product high quality sour cherry juice because this process does not require high temperature or pressure. Raw juice with approximately $15^{\circ} \mathrm{Brix}$ was used for the experiment and tried to concentrate up to $60^{\circ}$ Brix where the water activity low enough to inhibit the microbiological deterioration. Before and after the process, TPC (total phenolic compounds) and FRAP (ferric reducing antioxidant power) was measured using spectrophotometric methods to determine the effect of the osmotic distillation. Our results point out that osmotic distillation is a promising method to concentrate sour cherry juice and prevent the loss of valuable compounds.
\end{abstract}

Key words: fruit juice, membrane concentration, osmotic distillation, sour cherry

\section{Introduction}

Osmotic distillation is a kind of mass transfer driven membrane process where the driving force is the vapour pressure difference between two solutions. Similar that membrane distillation (MD) in case of OD is also used hyrdophobic, porous, polymeric membranes. For the osmotic distillation process usually high concentration of osmotic agent, mostly salt solution $\left(\mathrm{NaCl}, \mathrm{CaCl}_{2}, \mathrm{~K}_{2} \mathrm{HPO}_{4}, \mathrm{~K}-\right.$ acetate) or some kind of organic solutions (polyethyleneglycol, glycerol, etc.) is used which can keep and sustain very low value of vapour pressure during the process. These osmotic agents able to perform the suitable vapour pressure difference with the high concentration and low vapour pressure value between the two solutions (Bailey et al., 2000, Cassano et al., 2007; Gostoli et al., 1999; Hongvaleerat et al., 2008). OD process based on a phenomenon: between two aqueous solutions, which have different water activities a volatile compound stream occurs to equalize the vapour pressure different of the two solutions. In case of OD, a microporous hydrophobic membrane is present between these solutions which separates them from each other because of its hydrophobicity and surface energy. Thus, aqueous solutions cannot penetrate into the pores but volatile compound molecules (water) evaporate from the higher water activity liquid-vapour interface (liquid food side) across the pores by diffusion and condense at the lower water activity vapour-liquid interface (osmotic agent side). Figure 1 shows the flow sheet of the osmotic distillation process (Bélafi-Bakó et al., 2007; Courel et al., 2000; Mansuori et al., 1999; Thanedgunbaworn et al., 2007.)

Low operating temperature (ambient temperature) and atmospheric pressure can be facilitated to concentrate diluted aqueous solutions, which contain valuable heat-sensitive compounds. In case of fruit juice production, several reports have suggested the applications and possibilities of osmotic distillation to replace high energy demand evaporation. Although the implementation of such a technique at an industrial scale is not yet realized, a variety of fruit juice concentrations was performed experimentally by using OD and showed the potential of osmotic distillation. Cassano \& Drioli (2007) examined concentration of kiwi juice. Thanedgunbaworn et al. (2007) clarified passion fruit juice. Rodriges et al. (2004) concentrated camu-camu juice and Hongvaleerat et al. (2008) concentrated pineapple juice using osmotic distillation. Experimental results showed that 


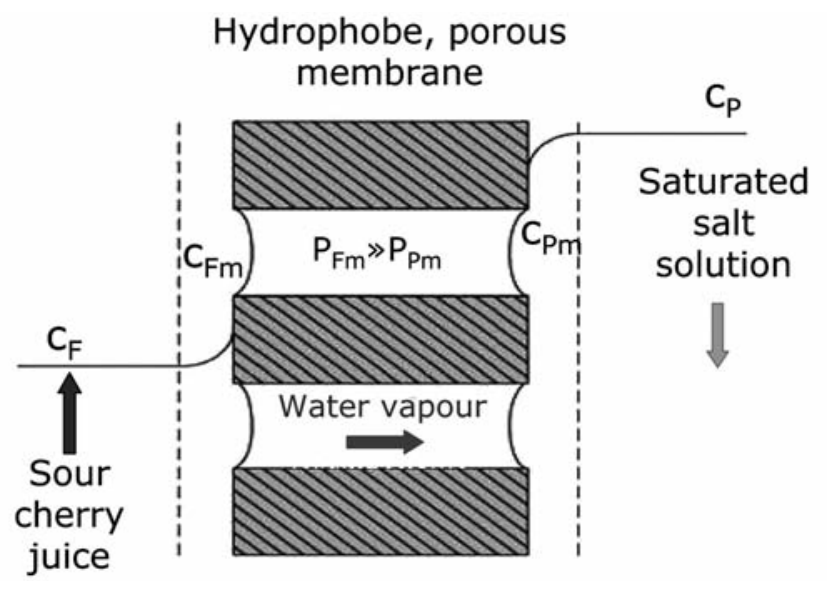

Figure 1. Flow sheet of osmotic distillation

the operation temperature has significant effects on distillate flux. Moreover, the distillate flux decreased during the process, which is due to the increasing total soluble solid content generated by the decreasing driving force. Similarly to other membrane separation processes, temperature increases the distillate flux during osmotic distillation. A commonly used rule states that an increase of $1{ }^{\circ} \mathrm{C}$ causes $\sim 3 \%$ increase in distillate flux. A limit exists in temperatureincrease, which is due to the temperature tolerance of the applied membrane materials (polymeric membranes) and heat degradation of valuable compounds. The increase of the recirculating flow rate decreases the thickness of the boundary layer and the effect of the concentration polarization on both sides of the membrane. As a result it is possible to increase the distillate flux with the increasing recirculating flow rate to a limited value.

Our analysis was carried out to check how efficiently sour cherry juice can be concentrated using osmotic distillation in order to produce fruit juices with health-promoting effects.

\section{Materials and methods}

For concentrating, 'Oblachinska' sour cherry juice was used. The initial concentration of juice was $14.7^{\circ} \mathrm{Brix}$ total solid content (mainly sucrose), the initial mass was $2500 \mathrm{~g}$. Juice was circulating in the capillars. Saturated $(43 \mathrm{~m} / \mathrm{m} \%)$ $\mathrm{CaCl}_{2}$ solution was used as osmotic agent.

- Membrane properties were: $0.2 \mathrm{~m}^{2}$ membrane area, $0.1 \mu \mathrm{m}$ pore size.

- Recirculating flow-rate: $361 / \mathrm{h}$ on each side.

- Operation temperature: $30^{\circ} \mathrm{C}$ on each side.

Figure 2 shows the laboratory osmotic distillation equipment and illustrates the operation of the concentration process. The difference in the vapour pressure between the two sides of the membrane (the juice and osmotic agent) is the driving force of the process and hence solutions could not penetrate the membrane. Two thermostates were used to keep temperature stagnant in both solutions. The increasing mass of the osmotic solution during the process was measured by digital balance and registered by a PC.

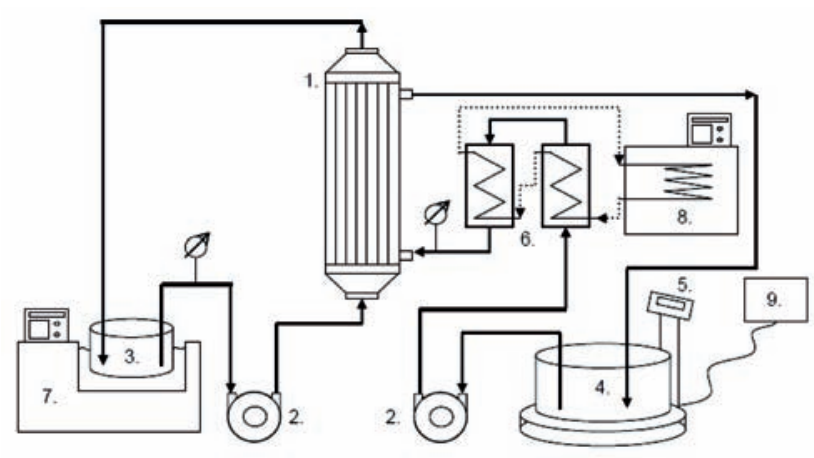

Figure 2. Laboratory scale osmotic distillation equipment. 1. membrane module, 2. peristaltic pumps, 3. sour cherry juice, 4. saturated $\mathrm{CaCl} 2$ solution 5. digital balance, 6. heat-exchanger, 7-8. thermostate, 9. PC.

To evaluate registered data, the flux values were calculated to determine the efficiency of the process according to the following equation:

where

$$
\mathrm{J}=\mathrm{m} /(\mathrm{A} * \mathrm{t})
$$

$\mathrm{m}$ is the mass of the distillate across the membrane (water), $\mathrm{kg}$

A is the membrane area, $\mathrm{m}^{2}$

$\mathrm{t}$ is the operation time, $\mathrm{h}$

The concentration process was performed in 3 separate steps and the osmotic solution had to be refreshed after every step to keep driving force higher. Each step was performed on a day. Figure 3 shows the changes in total solid content of the juice during the concentration process.

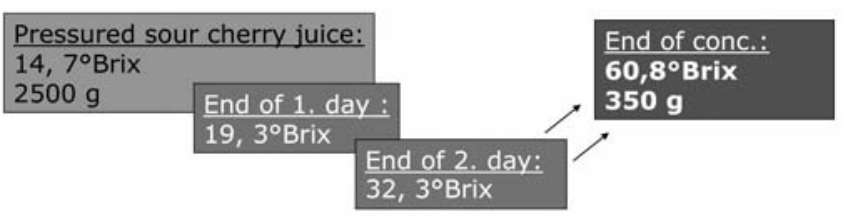

Figure 3. Concentration steps of sour cherry juice by osmotic distillation

\section{Antioxidant and total phenolic assays}

Antioxidant capacity was determined by the FRAP method (Benzie, \& Strain, 1996) and expressed as mmol ascorbic acid (AS)/L fruit juice or mol AA/100 g fresh weight. Total phenolic content (TPC) was measured using Folin-Ciocalteu's reagent according to the method of Singleton \& Rossi (1965). The content of soluble phenols was calculated from a standard curve based on gallic acid concentration (mg or mmol GSE/L).

\section{Results and discussions}

\section{Concetration process}

The sour cherry cultivar 'Oblachinska' was shown to possess relatively high antioxidant capacity among sour 
cherry commercial cultivars (Papp et al., 2010). Our analysis also confirmed its high antioxidant capacity and total polyphenol content (Figure 4), which is mainly due to its high anthocyanin content (Papp et al., 2010). These properties made 'Oblachinska' fruit juice a perspective raw material to test the effects of osmotic distillation. A microbiologically stable juice concentrate rich in health-promoting compounds might be of great economic value.
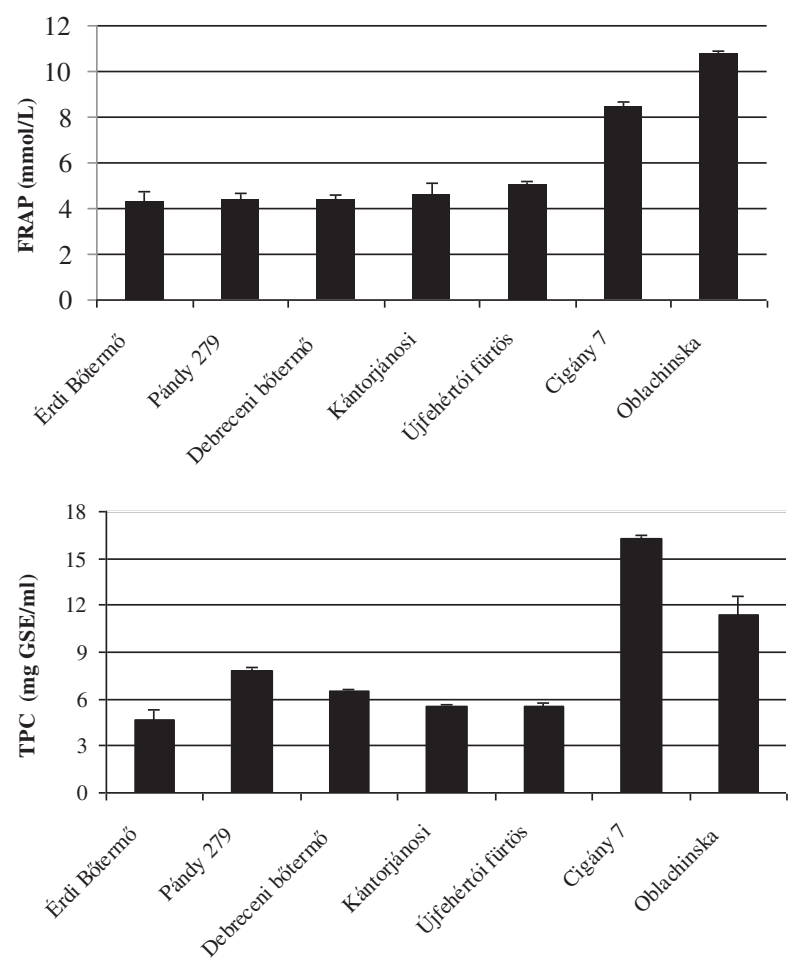

Figure 4. Antioxidant capacity and total phenol content of sour cherry juices

Figure 5 shows the whole concentration process of sour cherry juice. The system worked in batch process, total time of the treatment was $13.3 \mathrm{~h}$. The relatively low values of flux result from the low membrane area because the flux is strongly influenced by that. It is observed also that flux curves in all steps show decreasing trends because the osmotic solution is dilutes and the viscosity of juice increases. The final concentration of sour cherry juice was

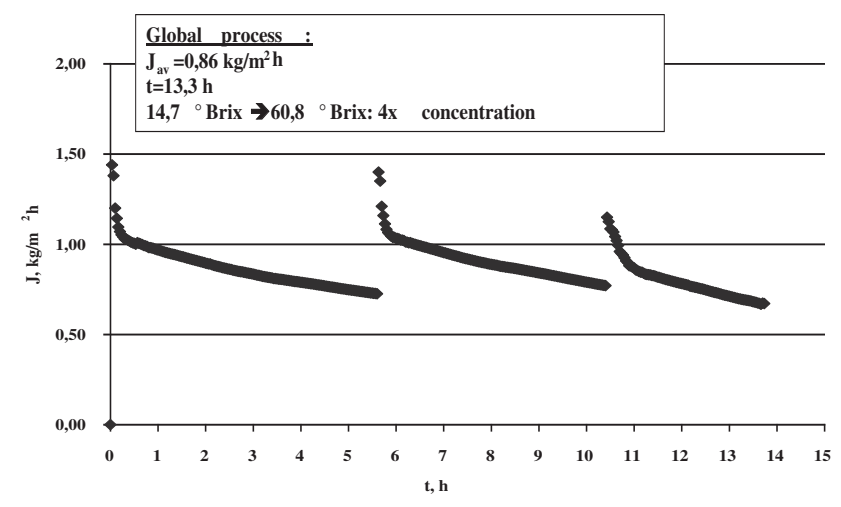

Figure 5. The concentration process of 'Oblachinska' sour cherry juice. $60.8^{\circ}$ Brix and the final viscosity was $70 \mathrm{mPas}$; therefore, moving the concentrated juice was much more difficult than initially.

\section{Analytical measurements}

To determine the effect of the osmotic distillation process, analytical methods were used. Figure 6 illustrates the FRAP antioxidant capacity (mmol ascorbic acid/l) before and after the treatment. It is clear that the process did not decrease the antioxidant capacity, which confirms that osmotic distillation might be a gentle way for sour cherry juice concentration.

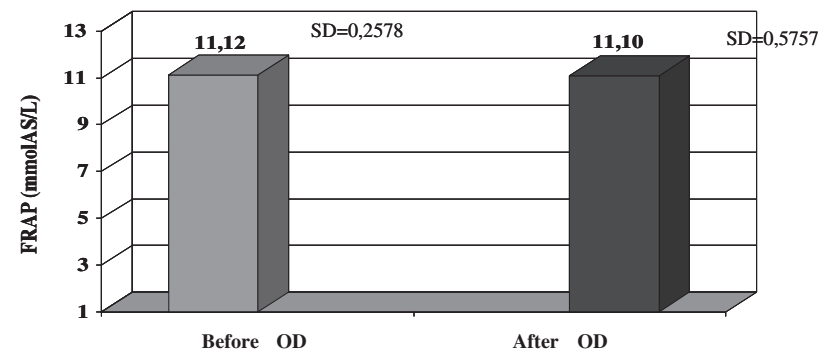

Figure 6. Osmotic distillation induced changes in total antioxidant capacity of 'Oblachinska' sour cherry fruit juice

Another interesting result indicates that total phenolic contents (mmol gallic acid/l) did not change during the concentration process (Figure 7).

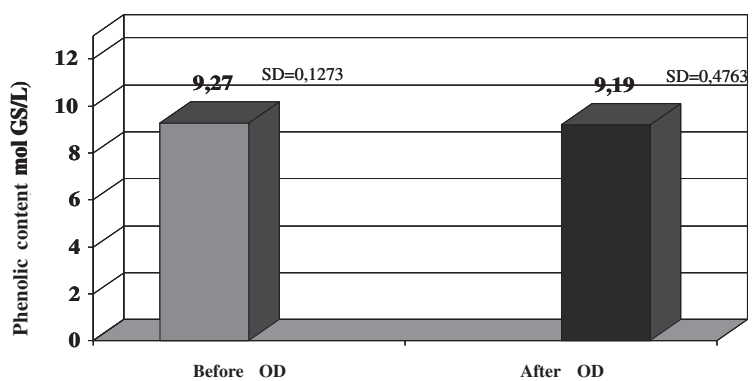

Figure 7. Osmotic distillation induced changes in total phenolic contents of 'Oblachinska' sour cherry fruit juice

\section{Conlusion}

The final concentration of sour cherry juice was 60.8 ${ }^{\circ}$ Brix; therefore, the process was suitable to concentrate sour cherry juice. The phenolic content and antioxidant capacity was the same before and after the osmotic distillation, so osmotic distillation is a suitable process to concentrate sour cherry juice without decreasing the contents of any analyzed health-related compounds.

\section{Acknowledgements}

This work was co-financed by the NFÜ TECH_08-A3/22008-0373, OTKA K84290 and TÁMOP-4.2.1/B-09/1/ 
KMR-grants. The authors thank Dr. Tibó Szabó for supplying the sour cherry samples. Attila Hegedüs is grateful for receiving a János Bolyai Scholarship, Hungarian Academy of Sciences and Éva Stefanovits-Bányai for the award Excellence in Science, Corvinus University of Budapest.

\section{References}

Bailey, A.F.G., Barbe, A.M., Hogan, P.A., Johnson, R.A., \& Sheng J. (2000): The effect of ultrafiltration on the subsequent concentration of grape juice by osmotic distillation, J. Membrane Sci. 164: 195-204.

Bélafi-Bakó K. (2007): From the osmotic power plant to semipermeable rain coat - membranes (In Hungarian). Magyar Tudomány. 8: 1024-1033.

Benzie, I.I.F. \& Strain, J.J. (1996): The ferric reducing ability of plasma (FRAP) as a measuring of "antioxidant power": The FRAP assay. Anal. Biochem. 239: 70-76.

Cassano, A., Conidi, C., Timpone, R., D’avella, M. \& Drioli, E. (2007): A membrane based process for the clarification and concentration of cactus pear juice. J. Food Eng. 80: 914-921.

Cassano, A. \& Drioli, E. (2007): Concentration of clarified kiwifruit juice by osmotic distillation. J. Food Eng. 79: 1397-1404.

Courel, M., Dornier, M., Rios, G.M. \& Reynes, M. (2000): Modelling of water transport in osmotic distillation using asymmetric membrane. J. Membrane Sci. 173: 107-122.
Gostoli C. (1999): Thermal effects in osmotic distillation. J. Membrane Sci. 163: 75-91.

Hongvaleerat, C., Cabral, L.M.C., Dornier, M., Reynes, M. \& Ningsanond, S. (2008): Concentration of pineapple juice by osmotic evaporation. J. Food Eng. 88: 548-552.

Mansouri J. \& Fane A.G. (1999): Osmotic distillation of oily feeds. J. Membrane Sci. 153: 103-120.

Papp, N., Szilvássy, B., Abrankó, L., Szabó, T., Pfeiffer, P., Szabó, Z., Nyéki, J., Ercisli, S., Stefanovits-Bányai, É. \& Hegedús, A. (2010): Main quality attributes and antioxidants in Hungarian sour cherries: identification of genotypes with enhanced functional properties. Int. J. Food Sci. Tech. 45: 395-402.

Rodrigues, R.B., Menezes, H.C., Cabral, L.M.C., Dornier, M., Rios, G.M. \& Reynes, M. (2004): Evaluation of reverse osmosis and osmotic evaporation to concentrate camu-camu juice (Myrciaria dubia). J. Food Eng. 63: 97-102.

Singleton, V.L. \& Rossi, J.A. (1965): Colorimetry of total phenolics with phosphomolybdic phosphotungstic acid „reagents”. Am. J. Enol. Vitic. 16: 144-158.

Thanedgunbaworn, R., Jiraratananon, R. \& Nguyen, M.H. (2007): Mass and heat transfer analysis in fructose concentration by osmotic distillation process using hollow fibre module. J. Food Eng. 78: 126-135.

Vaillant, F., Jeanton, E., Dornier, M., O'brien, G.M., Reynes, M. \& Decloux, M. (2001): Concentration of passion fruit juice on an industrial pilot scale using osmotic evaporation. J. Food Eng. 47: 195-202. 